\title{
Lapurdum
}

LAPURDUM Euskal ikerketen aldizkaria | Revue d'études basques |

Revista de estudios vascos | Basque studies review

$9 \mid 2004$

Numéro IX

\section{La ilustración en la vida literaria vasca del siglo XVIII}

Jesús-María Lasagabazter

\section{OpenEdition \\ Journals}

Edición electrónica

URL: http://journals.openedition.org/lapurdum/839

DOI: $10.4000 /$ lapurdum. 839

ISSN: 1965-0655

Editor

IKER

Edición impresa

Fecha de publicación: 1 noviembre 2004

Paginación: 149-157

ISBN: 2-68781-376-X

ISSN: $1273-3830$

Referencia electrónica

Jesús-María Lasagabazter, « La ilustración en la vida literaria vasca del siglo XVIII », Lapurdum [En línea], 9 | 2004, Publicado el 01 marzo 2009, consultado el 19 abril 2019. URL : http:// journals.openedition.org/lapurdum/839; DOI : 10.4000/lapurdum.839 


\title{
Lapurdum
}

9 (2004)

Numéro IX

Jesús-María Lasagabazter

\section{La ilustración en la vida literaria vasca del siglo XVIII}

\author{
Avertissement \\ Le contenu de ce site relève de la législation française sur la propriété intellectuelle et est la propriété exclusive de \\ l'éditeur. \\ Les œuvres figurant sur ce site peuvent être consultées et reproduites sur un support papier ou numérique sous \\ réserve qu'elles soient strictement réservées à un usage soit personnel, soit scientifique ou pédagogique excluant \\ toute exploitation commerciale. La reproduction devra obligatoirement mentionner l'éditeur, le nom de la revue, \\ l'auteur et la référence du document. \\ Toute autre reproduction est interdite sauf accord préalable de l'éditeur, en dehors des cas prévus par la législation \\ en vigueur en France.
}

\section{revues.org}

Revues.org est un portail de revues en sciences humaines et sociales développé par le Cléo, Centre pour l'édition électronique ouverte (CNRS, EHESS, UP, UAPV).

Référence électronique

Jesús-María Lasagabazter, «La ilustración en la vida literaria vasca del siglo XVIII », Lapurdum [En ligne], 9 | 2004, mis en ligne le 01 mars 2009, consulté le 11 octobre 2012. URL : http://lapurdum.revues.org/839; DOI : 10.4000/ lapurdum. 839

Éditeur : IKER UMR 5478

http://lapurdum.revues.org

http://www.revues.org

Document accessible en ligne sur : http://lapurdum.revues.org/839

Ce document est le fac-similé de l'édition papier.

Lasagabazter J.-M. | IKER 


\title{
La ilustración en la vida literaria vasca del siglo XVIII
}

\author{
Jesús-María LASAGABAZTER \\ Euskal-Herriko Unibertsitatea
}

Antes de entrar propiamente en la materia de mi ponencia, quiero hacer alguna precisión terminológica que me parece necesaria para aclarar el contenido de mi intervención.

En el programa mi intervención aparece titulada como Ilustra zioa XVIII mendeko euskal literaturan; y Les Lumières dans la littéra ture basque du XVIIIe Siècle.

Es decir, en las dos lenguas se habla de "literatura vasca".

El título que yo propuse -si mal no recuerdo-era La Ilustración en la vida litera ria vasca del siglo XVIII. En lugar de "literatura vasca", yo he preferido conscientemente utilizar la expresión "vida litera ria vasca". Tendré que dar alguna razón de mi preferencia.

La expresión "literatura vasca", en español me parece un tanto ambigua, porque no se corresponde semánticamente con la expresión, en euskera, "euskal literatura" ; por eso yo preferí titular mi último libro "las literaturas de los vascos", y no simplemente "literatura vasca". De la misma manera, yo suelo preferir hablar de "vida literaria" y no de "literatura". Porque por literatura tendemos a entender los textos literarios y sus autores, prescindiendo, al menos implícitamente, de las mediaciones o de los elementos en los que se contextualiza la existencia literaria en cuanto tal de los textos.

Por otra parte, el período en que se sitúa mi estudio - el siglo XVIII - y el movimiento que lo caracteriza - la Ilustración - no tiene una influencia decisiva en el desarrollo de la literatura euskérica, pero sí la tiene, como trato de hacer ver en este trabajo, en la vida literaria vasca.

Los historiadores de la literatura euskérica señalan como un dato que diferencia claramente el panorama literario vasco del XVIII en relación con el siglo anterior no en los textos que se producen, que siguen siendo predominantemente libros piadosos, que surgen, al menos primariamente, no de una voluntad literaria en el uso de la lengua, sino de una necesidad catequética en el contexto de la práctica pastoral de la iglesia y del clero que sigue siendo el autor único de este tipo de textos, sino el hecho de que el protagonismo "literario", de esta literatura piadosa, pasa de la región de Lapurdi a Guipúzcoa.

Si en el siglo XVII ya se ha escrito ese clásico de la literatura vasca que es el Gero de Axular, que ve la luz en el contexto de la llamada "Escuela de Sara", en el XVIII, 
por el contrario todos los libros piadosos que se publican en el País Vasco continental son sin excepción traducciones o adaptaciones de obras ya clásicas de la literatura ascética : la Imitación de Cristo, traducida en su primera versión completa por Michel de Chourio, párroco de San Juan de Luz y que conoce nada menos que cuatro ediciones a lo largo del siglo, la Introducción a la vida devota, de San Francisco de Sales, que había sido traducida ya por Silvain Pouvreau en el siglo XVII y que es traducida ahora, en 1749, por Haraneder, o el Ejercicio de perfección y virtudes cristianas, del Padre Alfonso Rodríguez, y del que el párroco de Ibarre hace un resumen en 1782 .

Es claro, pues, que el dialecto labortano, que obras como el Gero o el Manual devozionezkoa de Etxeberri de Ziburu habían elevado a la condición de lengua literaria, no encuentra en este siglo más campo de aplicación que la traducción o adaptación de obras anteriores. De ahí que más de un estudioso de nuestras letras hable incluso de una verdadera decadencia de la literatura labortana en el siglo XVIII.

Es conocida la tesis de Laffite que atribuye esta decadencia a las consecuencias que para el país vasco tuvo el tratado de Utrecht (1713) y la pérdida de Terranova y otros territorios ultramarinos, lo cual supone una notable pérdida de la floreciente industria pesquera y del comercio que la región de Lapurdi había mantenido con esos territorios de ultramar.

Otros autores se han limitado a repetir demasiado mecánicamente la interpretación de Laffite, aunque Mitxelena, a propósito del florecimiento literario guipuzcoano en el XVIII, coincidente con la expansión comercial matiza "sin establecer por ello una correlación muy estrecha entre fenómenos de orden muy distinto".

"Le malheur économique-concluye sentenciosamente Laffite - n'est pas favorable a ux Muses".

Creo, en todo caso, que se trata de una interpretación demasiado mecanicista de la relación entre la base económica de una sociedad y su superestructura literaria.

Además, y esto me parece especialmente importante, hablar de florecimiento o de decadencia literarios, no deja de resultar poco riguroso, ya que es claro que la actividad de escritura en Lapurdi en el XVII o en Guipúzcoa en el XVIII Mendiburu, Cardaveraz... - no obedece a motivaciones y objetivos propiamente literarios, sin o más bien pastorales, en el contexto de la catequesis de la Iglesia. Y Larramendi lo señala explícitamente en el prólogo de su Diccionario Trilingüe o de la Corografia. Porque tampoco la recepción de los libros de piedad de la literatura vasca de esos siglos es literaria, y ni siquiera lingüística, sino religiosa. Y es en el sistema de la práctica pastoral de la iglesia y del clero donde esos textos se identifican y encuentran su razón de existir como textos y su función.

Ahora bien, el hecho de adscribir estas obras no a un sistema literario en cuanto tal, sino a la práctica pastoral de la iglesia no quiere decir que sean ajenas a la literatura y que no deban ser incluidas en una historia de la literatura vasca. Muy al contrario, son esos textos precisamente los que constituyen el origen y el primer desarrollo de la prosa euskérica y consecuentemente de la prosa literaria.

Uno de los elementos decisivos en esta especie de "prehistoria" de la prosa literaria vasca es una nueva conciencia de la lengua, que había estado presente en los escritores vascos ya desde Etxepare - "euskara, ja lgi a di plazara" -. 
Esta "nueva" conciencia de la lengua, que funciona como justificación y estímulo de la tarea de escribir en euskera, se hace más refleja, se sistematiza y expresa en obras lingüísticas - gramáticas, diccionarios, apologías de la lengua... - a lo largo del siglo XVIII.

Joanes Etcheberri, con su Gomendiozko carta edo guthuna, dirigida al biltzar de Laburdi, y sobre todo Manuel de Larramendi, pueden ser considerados como precursores de alguna manera del espíritu de la llustración.

Las preocupaciones lingüísticas de Larramendi - origen del lenguaje, parentesco lingüístico, lengua universal ...- ocupan un lugar importante y coinciden con las preocupaciones intelectuales de su tiempo. No hay más que recordar las figuras de Feijóo y Hervás, Sarmiento, Mayans o Arteaga.

Larramendi - su espíritu, sus ideas, sus preocupaciones - le hacen un precursor señalado de los famosos "Caballeritos de Azcoitia", y del clima cultural que cristaliza, coincidiendo casi con su muerte, en la creación, por el Conde de Peñaflorida, de la Real Sociedad Bascongada de los Amigos del País.

Y aunque Larramendi escribió la casi totalidad de su obra en castellano, tuvo una gran influencia, como lo ha señalado Mitxelena, en la publicación de numerosos libros vascos, primero de devoción y después también amenos, en Guipúzcoa, Vizcaya y Navarra. Hasta el punto de que se puede decir que no es posible hablar de la literatura vasca - castellana, pero también euskérica - sin aludir a la existencia, la obra y la influencia de la Real Sociedad Bascongada de los Amigos del País.

Si bien es cierto que la preocupación mayor de la actividad de la Real Sociedad fue el dominio de las ciencias naturales, también la literatura - las Bellas Letras como se dice en el artículo primero de los Estatutos, constituye centro de preocupación de los Amigos del País. (Es esencial a este respecto el interesante y documentado estudio de Luis María Areta Armentia La obra literaria de La Real Sociedad Vascongada de los Amigos del País, de 1976).

Es en el artículo IX de los Estatutos de la Bascongada donde se alude al cultivo de las Bellas Letras:

"...unos se dedicarán a la Historia Sagrada y Profana, otros a la elocuencia, otros a la Poesía castellana en general, ya sea componiendo sobre asuntos determinados, ya baciendo alguna versión de algún célebre Poema escrito en otro Idioma, o ya reproduciendo las obras de algún famoso Poeta español que sean poco conocidas, otros se aplicarán a pulir y cultivar la lengua bascongada" (el subrayado es mío).

Entre las diferentes comisiones en que se organiza la actividad de los Amigos hay una - la cuarta - que se denomina de Historia, Política y Buenas Letras ; además la clase de los Literatos constituye una de las diferentes categorías en que se agrupan los Amigos.

La obra literaria de los Amigos del País no es sino aplicación y resultado de una teoría literaria - una Poética - inspirada directamente en los grandes teóricos del neoclasicismo de la época : Boileau, Luzán, Montiano...

El texto programático es sin duda el discurso sobre el buen gusto en literatura, que pronuncia el Conde de Peñaflorida, con ocasión de la Asamblea Pública de los amigos del País, celebrada en Vitoria el 20 de enero de 1766. 
La teoría y la práctica literaria de los ilustrados vascos se inscribe así en el sistema literario neoclásico de la ilustración europea y más directamente de la española. Pragmatismo y didactismo son las categorías fundamentales a que obedece la actividad literaria en todos sus géneros, incluso en aquellos que, como la poesía, aparecerían más resistentes a una finalidad utilitaria. Es el horaciano "enseñar deleitando" de Horacio, "el Gran Príncipe del buen gusto", le llama Peñaflorida, cuya Ars Poetica funciona como el modelo principal del buen gusto literario en la concepción de los Ilustrados. Esto quiere decir que la obra literaria teórica y de creación se inscribe en un sistema literario y cultural distinto de lo que en esa misma época puede explicar la existencia, el funcionamiento y el sentido de la literatura euskérica. El siglo XVIII es por antonomasia el siglo de las poéticas : Boileau para Francia y Luzán para España encarnan este espíritu preceptista de la literatura neoclásica. En euskera no tenemos sino el texto de Ohiénart, L'Art Poétique Basque, que aunque escrito en 1665, permanece inédito e ignorado hasta 1967.

La motivación primera que impulsa a Larramendi a exaltar el euskera y a fomentar su uso escrito no es propiamente literaria, sino religiosa. Basta leer el prólogo del Diccionario Trilingüe o la Corografía, donde señala explícitamente que su propósito es promocionar la predicación y la enseñanza religiosa en vascuence y dignificarlas mediante un uso riguroso y digno de la lengua, al servicio de una catequesis eficaz de los fieles. Así, en el prólogo de su Diccionario, en el capítulo en que expone "cómo el bascuence es lengua elocuente", después de dar varias razones por las que se predica mal en vascuence, concluye :

Qué repetir! Qué trabucarse" Qué ni atinar con las voces del vascuence oportunas" Qué invertir conjugaciones y tiempos! Parece que esián haciendo burla del auditorio de la iglesia y de la palabra de Dios; y luego tienen el desabogo de decir que no da más de sí el vascuence.

Además, desde la perspectiva no de la literatura euskérica, sino de eso que al comienzo de esta intervención hemos denominado "vida literaria", hay que reivindicar también la importancia de la figura del ilustre jesuita guipuzcoano como escritor en castellano. Es seguramente Mitxelena el primero en lamentar que la figura de Larramendi haya sido olvidada en el panorama de la literatura castellana de su siglo. Pero sobre todo es Tellechea Idígoras el que, en la Introducción a la Corografía, se ocupa con bastante amplitud del estilo literario de Larramendi, y establece paralelismos de género con autores de la época como Feijoo, Isla o Sarmiento, concluyendo :

Sólo el desconocimiento explica que se silencie el nombre de Larramendi en las historias de la cultura y más específicamente de la literatura que disertan basta con suma amplitud de la época. Huelga citar nombres porque el silencio es universal y sin embargo yo quiero recabar un puesto bonroso para Larramendi en la consideración de los especialistas europeos y españoles del siglo XVIII ; y ello no sólo por su estilo literario, sino por su contenido".

Por lo que se refiere propiamente a la actividad literaria de la Bascongada, quiero aludir aquí a dos dominios claramente diferenciados, pero exponentes ambos del espíritu cultural de la Ilustración : me refiero a la actividad teatral en la que destaca el papel del Conde de Peñaflorida, y al cultivo de un género como la fábula, donde 
los ilustrados pueden evidentemente verificar la naturaleza didáctica y la función moralizante de la literatura.

El panorama teatral del XVIII español está centrado en los ataques al teatro barroco, y la polémica sobre los autos sacramentales hasta su prohibición. Este es el clima que explica las ideas de los Ilustrados vascos y la vida teatral de la Bascongada.

Nuestra reflexión se va a centrar en tres aspectos fundamentales : 1) las ideas sobre el teatro ; 2) la práctica teatral de la sociedad, y 3) la creación dramática de los Amigos del País.

La preceptiva dramática de los ilustrados vascos tiene su texto programático en el discurso que con el título Carta sobre el tea tro, publica Félix María de Samaniego, bajo el seudónimo de Cosme Damián, en El Censor de enero de 1786.

El principio neoclásico de la verosimilitud le lleva a Samaniego a proclamar la imitación de la naturaleza, la subordinación a la razón y la sumisión a las reglas dramáticas, como criterios definitivos del buen gusto dramático. Por eso hay una crítica demasiado global y poco matizada de los autores anteriores $\mathrm{o}$ contemporáneos -("los Lopes, Calderones, Moretos, etc.)- que deberían comparecer "ante el tribunal de la razón para responder del cargo de haber adoptado, promovido, acreditado y hecho casi invencible la forma viciosa de nuestro teatro". Es la misma posición que adoptan otros miembros de la Sociedad Bascongada, como Ignacio Luis de Aguirre, o el propio Peñaflorida, quien en su comedia La tertulia, refiriéndose a las malas obras teatrales, dice que hay que "desterrarlas y abolirlas del mundo".

Frente a esto el teatro que los ilustrados vascos defienden es el de los clásicos como Aristófanes, Plauto y Terencio, Sófocles y Eurípides, o el de autores modernos como Molière, Goldoni o Racine.

En coherencia con las posiciones teóricas y críticas de los Ilustrados, está la práctica teatral de la Sociedad.

La importancia que dan a la actividad teatral queda recogida en los estatutos de 1765 , donde se dice :

Las noches se destina rán a cultivar la música o la poesía dra mática, logrando por este medio el que ni a un en las diversiones se distraigan los a migos del Instituto.

Y un Reglamento regula con todo detalle la práctica de las representaciones teatrales, desde el lugar de la representación hasta la vestimenta de los actores, pasando por las personas que deben ser admitidas al espectáculo. Hay una concepción claramente elitista del teatro, ya que a las representaciones sólo son admitidos los miembros de la Sociedad, a los que se añaden, como invitados, la alta sociedad y los eclesiásticos de Vergara.

Hay una preferencia por obras de teatro lírico - zarzuela y ópera cómica - y se trata sobre todo de traducciones o adaptaciones de obras francesas o italianas. Según Areta, de las siete primeras obras representadas, sólo hay dos originales : $L a$ tertulia y El borracho burlado, ambas del Conde de Peñaflorida.

No me resisto a citar, aunque la cita sea larga, a Pedro Valentín de Mugartegui, cuando en sus Memorias de todas mis caminatas, andanzas y boberías y de algunos pasages memorables a caecidos en la gran villa de Marquina desde el año 1732, nos cuenta: 
El 3 de Febrero del año 64 fui a Vergara en compañía del Conde de Peñaflorida y otros, a las funciones de San Martín de Aguirre, y volví el día 8. Los siete días siguientes tuvimos una bella orquesta compuesta del Conde, Rocaverde, Gamarra, Sordel y Mazarredo, y c antaron varias arias y sainetes las tres hijas del Conde, las dos hermanas Ansoteguis, la Gertrudis Ozaeta, el sobrinito de Gamarra y nuestro organista... El 4 de junio fui a Azpeitia con el orga nista Ma rcos a los ensa yos de óperas y tragedias y volví el 9 del mismo, en compañía de don Félix María de Samaniego a pasar las Pascuas. El 13 del mismo pasamos a Azcoitia a continuar los ensayos hasta el 2 de julio y los cinco días siguientes de Juntas, en los que representamos la tragedia de Metasta ssio, intitula da La clemencia de Tito, traducida por don Joa quín Ma ría de Eguía y las dosóperas cómicas bufas intituladas El Mariscal en su Fragua y El borracho burlado, la 'primera traducida del francés y la segunda compuesta y puesta en música por don Xavier María de Munive, Conde de Peñaflorida. Los actores de la tragedia fueron : El Conde de Peñaflorida, don Joaquín María de Eguía, don Félix María de Sa maniego y don Pedro Valentín de Mugartegui. Las actrices Doña Ignacia de Munive. Los actores de las óperas fueron : el Conde de Peñaflorida, don Félix María de Samaniego, don Pedro Valentín de Mugartegui, Marcos Recalde y Xavier de Echevarría. Las actrices doña Josepha de Munive y Marianita Ba lzola... El 2 de septiembre fui a la fa mosa siestas de Verga ra, que empeza ron el 10 y se concluyeron el 15 ; hubo funciones de iglesia, cucañas, tres corridas, dos de Ca stilla y una de Navarra, hermososfuegos, carro triunfal, parejas, bella ilumina ción, y las dos famosas óperas el Mariscal Ferrant y Borra cho Burlado, que las representa mos los mismos actores que en Azcoitia menos Mari Pepa, en cuyo lugar entró la Gertrudis Ozaeta.

La actividad teatral de los ilustrados vascos es sin embargo de corta duración. La razón parece estar por un lado en la dedicación cada vez mayor a las ciencias útiles y a la enseñanza y en la oposición de determinadas instancias eclesiásticas, entre las que se cita explícitamente a los jesuitas.

El factotum de la actividad teatral de los Amigos del País es sin duda ninguna el propio Conde de Peñaflorida, que aparece cultivando todas las facetas que abarcan el arte dramático, desde preceptista a actor, pasando por la actividad de director, aunque ésta es una figura que no se conoce en el teatro hasta finales del XIX.

Pero la faceta más importante y decisiva que encarna Peñaflorida en el mundo del teatro en el contexto de la actividad de la Bascongada, es su condición de dramaturgo, sobre todo por lo que se refiere al teatro euskérico, porque están en euskera algunas partes - las partes cantadas, sobre todo - de El borracho burla do y El carnaval. Además de ese texto menor que con el título de Gabon sariac se publica en Azcoitia en 1762 y aparece firmado con el extraño seudónimo de Luisa de la Misericordia. El Conde es consciente de la conveniencia de hacer un uso más generalizado del euskera en su teatro, pero también se da cuenta de ciertas dificultades. Así, en el prólogo de El borracho burlado, nos dice :

... mi primera idea fue de que toda esta ópera fuese en vascuence, pero luego me faltó la dificultad del dialecto de que me habia de servir en ella. Si me valía del de Azcoytia, hubiera sido poco gra to a todo el resto del País (...) ; y si quería usar del dialecto de Tolosa, Hernani, San Sebastián, etc. exponía a los actores a hacerse ridículos...

Autores importantes como Mitxelena o Villasante atribuyen a Peñaflorida la paternidad de los Gabon sariac, aunque no falta (Manuel Lecuona) quien señala la autoría del P. Larramendi. Gabon sariac es una serie de villancicos destinados a la celebración de la Navidad de ese año. 
Si exceptuamos el teatro popular suletino, las piezas dramáticas de Peñaflorida son, junto con Gabonetako ikuskizuna de Pedro Ignacio de Barrutia, los primeros documentos en la historia del teatro vasco. Aunque se trata de autores contemporáneos, sus obras dramáticas suponen preceptivas o concepciones teatrales totalmente diferentes.

Peñaflorida se ajusta escrupulosamente a las convenciones dramáticas por la preceptiva neoclásica - verosimilitud, unidades dramáticas, uniformidad de género, función didáctico-moralizante... - frente a la libertad creativa del teatro barroco. Ejemplo de esta actitud puede ser la escrupulosidad con que el Conde, en El borracho burlado, trata de respetar las exigencias de la unidad de lugar, y así se ve obligado a justificar que si, en un momento de la comedia, la acción pasa de la tienda del zapatero a las habitaciones del marqués,

suponiéndose que el zapatero vivía en los cuartos bajos de este caballero, no se debe reputar por mutación de lugar

¿Cuál es en cambio la preceptiva dramática que subyace a la pieza de Barrutia ? No deja de sorprender que en una obra tan rudimentaria como Gabonetako ikuskizuna el personaje, en algún caso, sea la persona misma del actor, que se representaría a sí mismo, destruyéndose la dualidad actor-personaje, o, para decirlo más "pirandellianamente" planteando el problema de la frontera teatro-realidad. Esto le ha llevado a algún crítico a señalar que Barrutia se adelanta a su tiempo teatral y plantea una problemática teatral que sólo modernamente aparecerá explicitada, por ejemplo, en el teatro de Pirandello.

Creo que el paralelismo le viene demasiado grande a Barrutia o a quien sea el autor de Gabonetako ikuskizuna. Si no se respetan las unidades dramáticas, que tanta veneración suscitaban en los neoclásicos, no es porque se pretenda superarlas desde una preceptiva más libre de ataduras formales, sino sencillamente porque se desconocen ; lo cual, a mi juicio, es señal del arcaísmo de la pieza, más que marca de su pretendida modernidad.

Es cierto que en su ingenuidad de construcción dramática y en la libertad con que se trata la relación personaje-actor, la obra de Barrutia, por su indudable frescura teatral, puede dar la impresión de un cierto aire moderno. Pero es moderno en la medida en que no es de su tiempo -el neoclasicismo teatral-, sino más bien de un tiempo anterior, que podría incluso ser retrotraído hasta el drama litúrgico medieval.

Si no hay constancia ninguna de que Gabonetako ikuskizuna se hubiera representado, ni siquiera en Mondragón, de donde era escribano Pedro Ignacio de Barrutia, y sí la hay en cambio de la representación de las piezas teatrales de Peñaflorida, se puede decir en buena lógica que el teatro vasco sube por primera vez a los escenarios de la mano del Conde. Es una presencia parcial, ciertamente, pero es la primera históricamente, y no deja de ser un dato positivo que ilustra la presencia de la Ilustración vasca en la vida literaria del país.

***

Por fin quiero aludir a otro elemento que tiene cultivo y vitalidad en la actividad literaria de los ilustrados vascos y que es también decisivo en la literatura euskérica en los siglos XVIII y XIX. Me refiero al género de la fábula.

La fábula es un género poético que por sus características -sencillez, racionalidad y dimensión moralizante- responde de manera adecuada a lo que las corrientes 
ilustradas piden a la literatura. No es extraño por tanto que esta forma literaria tuviera un cultivo importante por parte de los ilustrados vascos.

Félix María de Samaniego, el mejor, sin duda, de los fabulistas vascos y uno de los mejores de la lengua castellana, dedica el primer libro de sus famosas Fábulas en verso castella no a los Caballeros Alumnos del Real Seminario Patriótico de Vergara, y en la dedicatoria aparece meridianamente el horaciano "prodesse et delectare", que es el leit motiv de toda la literatura de la Ilustración :

$$
\begin{aligned}
& \text { Que en estos versos tra to } \\
& \text { de daros un a sunto } \\
& \text { que instruya deleitando. }
\end{aligned}
$$

Pero no fue Samaniego el único fabulista vasco en la época de la Ilustración. Hay que citar también los nombres de Ibáñez de la Rentería y de Pablo de Xérica, aunque sus fábulas no han tenido la importancia y el eco de las de Samaniego.

Parece verosímil afirmar que la fábula de los ilustrados vascos y, más en concreto, de Samaniego, tuvo influencia en el cultivo bastante abundante que esta forma literaria tuvo en la literatura euskérica en el siglo XIX, aunque el primer libro de fábulas en prosa, los Ipui Onac de Vicenta Moguel, publicado en 1804, está basado muy directamente en el fabulista Esopo ; años más tarde, en 1842, Agustín Pascual de Iturriaga traduce las fábulas de Samaniego en sus Fábula s y otra s composiciones en verso vascongado; también, por esos años, es traducido el fabulista Lafontaine ; al suletino, por J.B. Archu en 1848, y al labortano, por Goyetche en 1852.

También Juan Antonio de Moguel escribió fábulas, aunque no pasan de ser en su mayoría traducciones o adaptaciones. Vicenta Moguel había incluido en su libro ocho fábulas de su tío, el cual, dice la sobrina, tenía escritas muchas fábulas en verso, de las que las ocho incluídas en Ipui Onac no son sino una muestra.

Y el propio escritor, en sus cartas a Vargas Ponce, le dice que ha trabajado "a versión vascongada" ya en prosa, ya en verso, no pocas fábulas de Esopo y Fedro.

Todos estos datos parecen indicar la popularidad que a comienzos del XIX tiene para los escritores vascos un género como la fábula, así como el conocimiento que tienen de los grandes fabulistas de otras literaturas : tanto de los clásicos - el griego Esopo y el latino Fedro -, como de los modernos - el francés Lafontaine o el vasco Samaniego.

Estos datos u otros que se podrían aportar parecen demostrar el interés que los escritores vascos manifiestan por la fábula literaria, muy superior al manifestado, documentalmente al menos, por otras formas literarias tan en boga en el XIX y más decisivas en el desarrollo de la literatura, como es la novela.

En el contexto de la literatura vasca de la época que nos ocupa, donde, sobre todo por lo que se refiere a la prosa, no se ha salido todavía de los libros ascéticos y de piedad, la fábula, en verso o en prosa, es un género "civil", profano, pero fuertemente definido y delimitado por su finalidad didáctica y moralizadora.

A mí se me ocurre pensar, como hipótesis que debería ser verificada con trabajos monográficos sobre el tema, que en ese proceso lento en la literatura vasca que va de la prosa ascética a la prosa narrativa, la fábula podría ser vista como una especie de mediación, tanto en el nivel formal como en el temático.

En lo formal, porque la estructura literaria de la fábula descansa sobre elementos de naturaleza narrativa - personajes, acción ..., y en lo temático por el fuerte 
didactismo que inspira en la fábula el desarrollo de la acción, orientada en todos los casos a la justificación y explicitación de la moraleja final.

Cuando, a finales del XIX y sobre todo principios del XX, el nacimiento de la novela vasca marca una nueva frontera en el proceso de institucionalización de la literatura vasca como sistema literario y cultural autónomo, el costumbrismo tiene como características importantes un profundo didactismo y una intención moralizadora, muy semejantes a los de la fábula, aunque se trate de universos y formas de aprehensión literaria de lo real muy diferentes.

Llegados aquí, es hora de sintetizar lo dicho en unos cuantos puntos, a modo de conclusión.

1- Hay que partir del dato de que en el siglo XVIII no hay prácticamente vida literaria -creación y recepción, reflexión teórica y crítica- que se exprese y manifieste en euskera. Ese catálogo de autores y de obras con que los actuales historiadores de la literatura vasca cubren el siglo XVIII no pertenece en su tiempo al sistema de la literatura, sino al de la actividad pastoral y catequética de la Iglesia. No son por tanto resultado y expresión de una vida, de una actividad propiamente literaria dicha y sentida como tal.

2- La única vida estrictamente literaria en el XVIII vasco es la que se desarrolla a través de los Amigos del País, en la Real Sociedad Bascongada y en el Real Seminario de Vergara, y de la que Xavier María de Munibe, Conde de Peñaflorida, es inspirador y protagonista principal a un tiempo.

3- Es evidente que la actividad literaria de los ilustrados vascos se inscribe directamente en el sistema de la literatura europea -española y francesacontemporánea : sus teorías poéticas, sus consideraciones críticas, su participación en las polémicas literarias de la época, su trabajo, en fin, propiamente creador.

4- Hay que lamentar, sin duda, que los Amigos del País y en concreto Peñaflorida no hubieran sido más sensibles a las posibilidades que un desarrollo real y específico del euskera podía haber ofrecido, más allá de esa conciencia refleja de la lengua que tan fuerte resonancia encuentra por ejemplo en un Manuel de Larramendi.

5- Recordemos, sin embargo, para evitar ambigüedades, que el "movimiento larramendiano" -si se puede en rigor hablar de "movimiento"- visto hoy, con la perspectiva que dan doscientos años de historia, como un impulso decisivo para el desarrollo del euskera en un cultivo no solamente lingüístico, sino también literario, sobre todo en el siglo XIX, no fue en su tiempo sino expresión de un afán religioso y misionero, muy particular y localizado. No olvidemos que tanto Larramendi como Cardaveraz y Mendiburu eran jesuitas y es desde su vocación de tales desde donde se explica en primera instancia su actividad de predicadores en euskera y de escritores.

Larramendi es de una visión y de un aliento creativo más amplio. Su obra supera con creces el reducido ámbito pastoral de los otros escritores eclesiásticos de su tiempo. Y a pesar de todo, no altera sustancialmente el planteamiento y los objetivos religiosos de lo escrito en euskera en el siglo XVIII. 